\title{
Article
}

\section{Longitudinal Analyses of the Reciprocity of Depression and Anxiety after Traumatic Brain Injury and Its Clinical Implications}

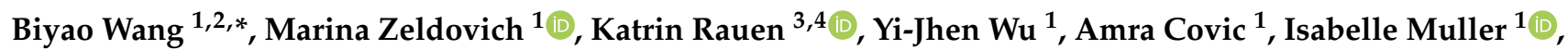 \\ Juanita A. Haagsma ${ }^{5,6}$, Suzanne Polinder ${ }^{5}$, David Menon ${ }^{7}$, Thomas Asendorf ${ }^{8}$, Nada Andelic ${ }^{9,10}{ }^{(D}$, \\ Nicole von Steinbuechel ${ }^{1}$ and CENTER-TBI Participants and Investigators ${ }^{\dagger, \ddagger}$
}

check for updates

Citation: Wang, B.; Zeldovich, M.; Rauen, K.; Wu, Y.-J.; Covic, A.; Muller, I.; Haagsma, J.A.; Polinder, S.; Menon, D.; Asendorf, T.; et al. Longitudinal Analyses of the Reciprocity of Depression and Anxiety after Traumatic Brain Injury and Its Clinical Implications. J. Clin. Med. 2021, 10, 5597. https://doi.org/ $10.3390 /$ jcm10235597

Academic Editor: Aaron S. Dumont

Received: 4 November 2021

Accepted: 25 November 2021

Published: 28 November 2021

Publisher's Note: MDPI stays neutral with regard to jurisdictional claims in published maps and institutional affiliations.

Copyright: (c) 2021 by the authors. Licensee MDPI, Basel, Switzerland. This article is an open access article distributed under the terms and conditions of the Creative Commons Attribution (CC BY) license (https:// creativecommons.org/licenses/by/ $4.0 /)$.
1 Institute of Medical Psychology and Medical Sociology, University Medical Center Goettingen, Waldweg 37A, 37073 Goettingen, Germany; marina.zeldovich@med.uni-goettingen.de (M.Z.); yi-jhen.wu@med.uni-goettingen.de (Y.-J.W.); amra.covic@med.uni-goettingen.de (A.C.); isabelle.mueller@med.uni-goettingen.de (I.M.); nvsteinbuechel@med.uni-goettingen.de (N.v.S.)

2 Division of Psychology and Language Sciences, University College London, London WC1H 0AP, UK

3 Department of Geriatric Psychiatry, Psychiatric Hospital Zurich, University of Zurich, Minervastrasse 145, 8032 Zurich, Switzerland; katrin.rauen@uzh.ch

4 Institute for Stroke and Dementia Research (ISD), University Hospital, LMU Munich, Feodor-Lynen-Straße 17, 81377 Munich, Germany

5 Department of Public Health, Erasmus MC, University Medical Center Rotterdam, 3000 CA Rotterdam, The Netherlands; j.haagsma@erasmusmc.nl (J.A.H.); s.polinder@erasmusmc.nl (S.P.)

6 Department of Emergency Medicine, Erasmus MC, University Medical Center Rotterdam, 3000 CA Rotterdam, The Netherlands

7 Division of Anaesthesia, University of Cambridge/Addenbrooke's Hospital, Box 157, Cambridge CB2 0QQ, UK; dkm13@cam.ac.uk

8 Department of Medical Statistics, University Medical Center Goettingen, 37073 Goettingen, Germany; thomas.asendorf@med.uni-goettingen.de

9 Department of Physical Medicine and Rehabilitation, Oslo University Hospital, 0424 Oslo, Norway; NADAND@ous-hf.no

10 Research Centre for Habilitation and Rehabilitation Models and Services (CHARM), Faculty of Medicine, Institute of Health and Society, University of Oslo, 0373 Oslo, Norway

* Correspondence: Biyao.Wang@med.uni-goettingen.de

+ Membership of the CENTER-TBI Participants and Investigators is provided in the Acknowledgments.

$\ddagger$ The full list of the CENTER-TBI participants and investigators is provided in the Online Supplement.

Abstract: Depression and anxiety are common following traumatic brain injury (TBI). Understanding their prevalence and interplay within the first year after TBI with differing severities may improve patients' outcomes after TBI. Individuals with a clinical diagnosis of TBI recruited for the large European collaborative longitudinal study CENTER-TBI were screened for patient-reported major depression (MD) and generalized anxiety disorder (GAD) at three, six, and twelve months post-injury $(\mathrm{N}=1683)$. Data were analyzed using autoregressive cross-lagged models. Sociodemographic, premorbid and injury-related factors were examined as risk factors. 14.1-15.5\% of TBI patients reported moderate to severe MD at three to twelve months after TBI, 7.9-9.5\% reported GAD. Depression and anxiety after TBI presented high within-domain persistency and cross-domain concurrent associations. MD at three months post-TBI had a significant impact on GAD at six months post-TBI, while both acted bidirectionally at six to twelve months post-TBI. Being more severely disabled, having experienced major extracranial injuries, an intensive care unit stay, and being female were risk factors for more severe MD and GAD. Major trauma and the level of consciousness after TBI were additionally associated with more severe $\mathrm{MD}$, whereas being younger was related to more severe GAD. Individuals after TBI should be screened and treated for MD and GAD early on, as both psychiatric disturbances are highly persistent and bi-directional in their impact. More severely disabled patients are particularly vulnerable, and thus warrant timely screening and intensive follow-up treatment. 
Keywords: major depression; generalized anxiety disorder; traumatic brain injury; longitudinal; reciprocal relationship

\section{Introduction}

Worldwide, more than 50 million people experience a traumatic brain injury (TBI) every year, and it is estimated that about half the world's population will suffer at least one TBI over their lifetime [1]. Depression and anxiety are the most frequently observed mental health disorders after TBI [2-4]. Some plausible explanations of the emergence of post-injury depression and anxiety include the fear of higher mortality rate [5], heightened stress reactivity and enhanced fear sensitivity [6], disruption of neural circuits [7], and post-traumatic changes of neurotransmitters in the brain [8]. A large meta-analysis reported that $27 \%$ of patients were clinically diagnosed with depression following TBI and $38 \%$ of clinically significant levels of depression assessed with patient-reported outcome measures (PROMs) [9]. A further meta-analysis on anxiety reported that around $11 \%$ of patients after TBI were diagnosed with a generalized anxiety disorder (GAD) and 37\% reported clinically significant levels of anxiety according to PROMs [10]. The neglect and undertreatment of such psychiatric problems is reported to hamper patients' recovery, interfere with their mental health [11], and elevate the risk of a long-term chronic health condition [12], poorer social functioning [13], lower quality of life [14,15], and increased health-care costs [16].

In general, post-traumatic depression and anxiety have been reported in a large body of literature [2,17-22]. They are either treated as two subfactors of a general underlying distress factor [23] assessed using composite scales [24,25], or as two distinct diseases diagnosed by means of the International Classification of Diseases (ICD-10) [26] or Diagnostic and Statistical Manual of Mental Disorders (DSM-5) [27], or separate scales, requiring differential diagnosis and treatment. Longitudinal investigations of coexisting depression and anxiety after TBI are scarce and dominated by measuring their prevalence. A limited number of studies have attempted to address the joint developmental patterns of depression and anxiety post TBI: Barker-Collo et al. [28] have reported multiple trajectories for patient-reported anxiety and depression across a four-year time span in individuals after mild TBI, whereby the largest proportion of respondents experienced anxiety and depression within the first year post-injury. Using a group-based trajectory model, Ren et al. [29] have demonstrated strong associations between continuously high symptoms of patient-reported depression and anxiety in individuals after severe TBI within two years post-injury. A few studies used the cross-lagged panel design to investigate the reciprocity of the two conditions, focusing on the temporal relationship between functional disability and mental health while assessing patient-reported depression and anxiety separately [30] or jointly [31]. However, the longitudinal differential interplay between depression and anxiety post-TBI, once their persistence and coexistence have been accounted for, remains unclear. The high rates and the risk of psychiatric disturbance occurring within the first year after TBI demonstrated by previous studies $[2,32]$ suggest that a better understanding of their reciprocity in this period could shed light on the causal relationship between these two domains. Such knowledge may inform patients, caregivers, and professionals on targeted interventions, health management, and prevention strategies.

In addition, the evidence as to which factors are associated with higher levels of depression and anxiety following TBI is inconsistent [33] and limited by small sample sizes [34-37]. Investigations into the impact of extracranial injuries on depression and anxiety in individuals after TBI are scarce, for example. To our knowledge, only one study has investigated this topic, concentrating on patient-reported depression at six months postinjury [38]. The comprehensive exploration of potential risk factors will further optimize early screening, support vulnerable patients, and allow suitable participants to be recruited for interventional/clinical trials. 
The current study therefore aims (1) to explore the reciprocal relationship between patient-reported major depression (MD) and GAD over time and (2) to examine risk factors for more severe perceived depression and anxiety after TBI.

\section{Methods}

\subsection{Participants}

The participants included in these analyses were part of the prospective longitudinal observational study of Collaborative European NeuroTrauma Effectiveness Research in Traumatic Brain Injury (CENTER-TBI) $[39,40]$. Data were extracted from the CENTER Core 2.0 dataset. The core study comprised 4509 patients with a clinical diagnosis of TBI, who were enrolled at 63 different medical centers in 17 European countries and Israel. Participants had a clinical diagnosis of TBI and a clinical indication of a cerebral computed tomography (CCT), presented within $24 \mathrm{~h}$ of the injury and provided their informed consent, obtained in line with local and national requirements, and displayed no severe pre-existing neurological disorders [39]. The participants included were assigned to one of three clinical care pathways: admitted to the Emergency Room (ER), to a hospital ward (ADM), or to the intensive care unit (ICU). Data collection was carried out either at the hospital, through face-to-face or telephone interviews, or via postal mail. Further details have been published elsewhere [40]. The current study included participants who had filled in PROMs concerning depression and anxiety screening for at least two time points of the three, six and twelve months assessments after TBI. Individuals with premorbid psychiatric problems were excluded from the analyses to avoid a confounding bias.

\subsection{Ethical Approval}

The CENTER-TBI study was conducted in conformance with all relevant local national ethical guidelines and regulatory requirements for recruiting human subjects, as well as with relevant data protection and privacy regulations, and patients gave their informed consent. The study obtained ethical clearance from the relevant institutions both in the EU and in all the countries involved in the project (for a list of sites, ethical committees, and ethical approval details, see https:/ / www.center-tbi.eu/project/ethical-approval accessed on 4 November 2021).

\subsection{Measures}

Patients' sociodemographic information, including their age, sex, employment status, relationship status, education level, as well as details of their clinical pathway and preinjury psychiatric problems, was collected at baseline. The Glasgow Coma Scale (GCS) was used to characterize the level of consciousness and severity of TBI [41]. Major trauma was measured using the Abbreviated Injury Scale (AIS) [42] and defined as positive for Injury Severity Scores (ISS) $\geq 16$ [43]. Major extracranial injury (MEI) was used to categorize major injury in the non-head and neck regions [44] and defined as positive when AIS items in those regions displayed scores $\geq 3$. Functional disability and recovery was rated using the Glasgow Outcome Scale-Extended (GOSE) [45] after TBI. For further details, see Online Supplemental Notes 1.1-1.2.

The Patient Health Questionnaire-9 (PHQ-9) is a patient-reported MD screener with nine items based on the DSM-IV criteria [46] using a four-point Likert scale indicating no symptoms $(0=$ not at all $)$ to MD symptoms nearly every day ( 3 = nearly every day $)$ and a two-week frame of reference. The sum score (0 to 27) comprises all items. PHQ-9 scores of 5, 10, 15, and 20 indicated mild, moderate, moderately severe, and severe depression [46]

The General Anxiety Disorder-7 (GAD-7) [47] measures patient-reported GAD based on DSM-IV criteria with seven items on a four-point Likert scale $(0=$ not at all to $3=$ nearly every day) and a two-week frame of reference. The sum score comprises all items. GAD-7 scores of 5, 10, and 15 indicated mild, moderate, and severe levels of anxiety [47]. 


\subsection{Statistical Analysis}

Patient-reported MD and GAD at three, six, and twelve months after TBI, as well as potential risk factors, were examined descriptively (see Online Supplemental Notes 2.1) and then as unobserved latent variables in a structural equation modelling (SEM) framework [48]. Their longitudinal measurement invariance (MI) was tested as a prerequisite for the following analyses (see Online Supplemental Notes 2.2) and their longitudinal reciprocity was examined using autoregressive cross-lagged (ARCL) models [49-51]. Here, autoregressive (AR) effects describe the impact of a construct on itself measured at a later time point, whereby larger AR coefficients indicate little inter-individual variance from the previous time point, i.e., greater stability [52]. Cross-lagged (CL) effects also describe the influence of one construct on another measured at later time points, after controlling for their concurrent and AR effects. A series of nested ARCL models were compared with multiple model fit criteria to identify the best fit with the data (see Online Supplemental Notes 2.3).

Potential risk factors were separately added to the optimal ARCL model as covariates, to investigate how they were associated with the level of MD and GAD. Two types of factors were examined: sociodemographic (i.e., age, sex, employment status, relationship status, and education level) and injury-related (i.e., clinical pathway, GCS, MEI, major trauma, and GOSE) (see Online Supplement 2.4).

Longitudinal tests of MI and ARCL models were conducted using Mplus, version 7.3 [53]. The weighted least square mean and variance adjusted (WLSMV) estimation dealt with categorical data [54] and full information maximum likelihood estimation with missing data. Descriptive analyses were carried out using $R$ version 3.6.1 [55]. A two-tailed $p<0.050$ was considered statistically significant. Multiple testing was adjusted using a Bonferroni correction, in which the significance threshold (0.050) is divided by the number of tests performed.

\subsection{Role of the Funding Source}

The funder of the study had no role in study design, data collection, data analysis, data interpretation, or the writing of the report. The corresponding author had full access to all the data in the study and had final responsibility for the decision to submit for publication.

\section{Results}

\subsection{Descriptive Statistics}

The effective sample consisted of 1683 participants (see Figure 1 for a flowchart). Compared to this sample, those excluded from the study were more frequently unemployed, not in a stable relationship, less educated, recruited in the ER, more severely disabled, and reported higher levels of depression and anxiety after TBI (Online Supplemental Tables S1 and S2). If the 928 participants excluded, $34.3 \%$ had psychiatric problems prior to the TBI (Online Supplemental Table S3).

The sociodemographic characteristics are presented in Table 1. More individuals in the sample were male $(66.5 \%)$, middle-aged or older (age $\mathrm{M}=49.25, \mathrm{SD}=19.55)$, educated (years of education $\mathrm{M}=13.89, \mathrm{SD}=4.13$ ), employed (58.0\%), and in a stable relationship (56.5\%). Proportionally fewer individuals (19.0\%) were from the ER, $40.3 \%$ from the ADM, and $40.7 \%$ from the ICU sample. The unbalanced distribution across clinical pathways was to some extent design-related, since the study design required patients admitted to the ER to be assessed at three and six months, but not at twelve months after TBI (see Table S4 for detailed response rates). About $11.7 \%$ had experienced psychiatric problems before the TBI (Online Supplemental Table S4). Half of the sample had a major trauma (50.1\%), the majority of the participants sustained a mild TBI (76.6\%), had no MEI (69.7\%), and displayed good recovery six months after TBI (66.2\%). 


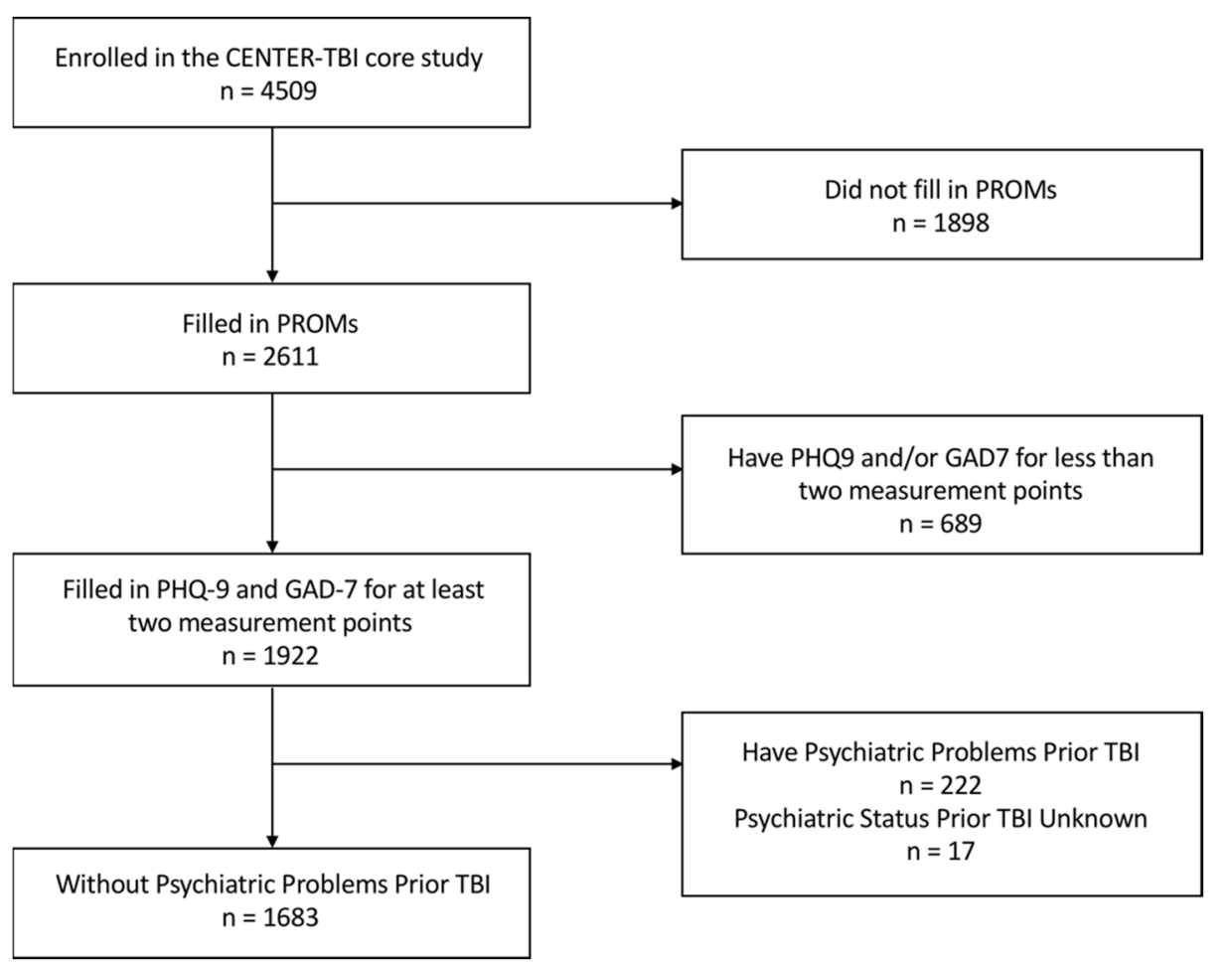

Figure 1. Attrition flowchart. PROM = patient-reported outcome measure; $P H Q-9=$ Patient Health Questionnaire-9; and GAD-7 = General Anxiety Disorder-7.

Patient-reported symptoms of MD and GAD are shown on the scale level in Table 2 and on the item level in Online Supplemental Table S5. Among all participants, mean scores of MD decreased significantly from three to six months after TBI $\left(t_{3 m-6 m}(1435)=3.98\right.$, $p<0.0001)$ and remained stable after that $\left(t_{6 m-12 m}(1072)=-0.22, p=0.83\right)$. Similar patterns were found for GAD over time $\left(t_{3 m-6 m}(1431)=2.09, p=0.036 ; t_{6 m-12 m}(1077)=0.24, p=0.81\right)$. Overall, $23.3 \%$ and $14.1 \%$ of the participants reported moderate to severe MD and GAD at least at one time point within twelve months after TBI. The prevalence of having moderate to severe levels of psychiatric problems at three, six, and twelve months was $15.5 \%, 14.1 \%$, and $15.5 \%$ for MD (i.e., PHQ-9 score $\geq 10$ ) and $9.5 \%, 7.9 \%$, and $8.0 \%$ for GAD (i.e., GAD-7 score $\geq 10$ ), respectively. The prevalence of different severity levels of MD and GAD (i.e., mild, moderate, moderately severe, and severe) for to different severity/cut-offs is shown in Table 2. Patients with and without concomitant MEI showed no significant difference in the rate of moderate to severe MD or GAD (Online Supplemental Table S6). Limited information was available concerning corresponding treatment during rehabilitation. Data concerning the use of psychological services were collected for only $22.9 \%$ of the participants (Online Supplemental Table S7). Among patients with moderate to severe MD or GAD at any time point after TBI, less than $40 \%$ received any psychological services during rehabilitation. 
Table 1. Demographic characteristics of the effective sample $(\mathrm{N}=1683)$.

\begin{tabular}{|c|c|c|}
\hline & Number/Mean Score & $\begin{array}{c}\text { Percentage/Standard } \\
\text { Deviation }\end{array}$ \\
\hline Female & 563 & $33.5 \%$ \\
\hline Age ${ }^{1}$ & 49.25 & 19.55 \\
\hline \multicolumn{3}{|l|}{ Age group } \\
\hline Adolescent (16-24) & 263 & $15.6 \%$ \\
\hline Young adult (25-34) & 198 & $11.8 \%$ \\
\hline Adult (35-44) & 220 & $13.1 \%$ \\
\hline Middle age (45-54) & 280 & $16.6 \%$ \\
\hline Upper middle age (55-64) & 291 & $17.3 \%$ \\
\hline Senior $(\geq 65)$ & 431 & $25.6 \%$ \\
\hline Years of education ${ }^{1}$ & 13.95 & 4.15 \\
\hline \multicolumn{3}{|l|}{ Education level } \\
\hline None & 13 & $0.9 \%$ \\
\hline Currently studying & 45 & $2.9 \%$ \\
\hline Primary school & 187 & $12.2 \%$ \\
\hline Secondary/high school & 529 & $34.6 \%$ \\
\hline Post high school training & 309 & $20.2 \%$ \\
\hline College/university & 446 & $29.2 \%$ \\
\hline \multicolumn{3}{|l|}{ Employment status } \\
\hline Employed, full-time & 739 & $46.2 \%$ \\
\hline Employed, part-time & 132 & $11.4 \%$ \\
\hline Sick leave & 6 & $0.4 \%$ \\
\hline Unemployed & 91 & $5.7 \%$ \\
\hline Retired & 399 & $24.9 \%$ \\
\hline Student & 166 & $10.4 \%$ \\
\hline Homemaker & 17 & $1.1 \%$ \\
\hline \multicolumn{3}{|l|}{ Relationship status } \\
\hline Never been married & 481 & $29.7 \%$ \\
\hline Married & 762 & $47.1 \%$ \\
\hline Living together & 152 & $9.4 \%$ \\
\hline Divorced & 115 & $7.1 \%$ \\
\hline Separated & 29 & $1.8 \%$ \\
\hline Widowed & 78 & $4.8 \%$ \\
\hline \multicolumn{3}{|l|}{ Clinical pathway } \\
\hline ADM & 679 & $40.3 \%$ \\
\hline ER & 319 & $19.0 \%$ \\
\hline ICU & 685 & $40.7 \%$ \\
\hline GCS score $^{1}$ & 12.85 & 3.74 \\
\hline \multicolumn{3}{|l|}{ GCS category } \\
\hline Mild & 1252 & $76.6 \%$ \\
\hline Moderate & 123 & $7.5 \%$ \\
\hline Severe & 259 & $15.9 \%$ \\
\hline MEI & 510 & $30.3 \%$ \\
\hline Major trauma & 838 & $50.1 \%$ \\
\hline GOSE score ${ }^{1,2}$ & 6.77 & 1.42 \\
\hline \multicolumn{3}{|l|}{ GOSE category } \\
\hline Good recovery & 1114 & $66.2 \%$ \\
\hline Moderate disability & 415 & $24.7 \%$ \\
\hline Severe disability & 154 & $9.2 \%$ \\
\hline
\end{tabular}


Table 2. Descriptive statistics and correlations between the PHQ-9 and the GAD-7 at the scale level.

\begin{tabular}{|c|c|c|c|c|c|c|c|c|c|}
\hline & \multirow[b]{2}{*}{$\mathbf{N}$} & \multirow[b]{2}{*}{$\begin{array}{c}\text { Cronbach's } \\
\alpha \\
\end{array}$} & \multirow[b]{2}{*}{ Mean } & \multirow[b]{2}{*}{ SD } & \multirow[b]{2}{*}{$\begin{array}{c}\text { Min-Max } \\
{[Q 1, Q 2, Q 3]}\end{array}$} & \multicolumn{4}{|c|}{ Prevalence * } \\
\hline & & & & & & Mild & Moderate & $\begin{array}{c}\text { Moderately } \\
\text { Severe }\end{array}$ & Severe \\
\hline (1) PHQ-9 at $3 \mathrm{~m}$ & 1519 & 0.86 & 4.71 & 4.89 & $0-25[1,3,7]$ & $24.9 \%$ & $9.7 \%$ & $4.5 \%$ & $1.30 \%$ \\
\hline (2) PHQ-9 at $6 \mathrm{~m}$ & 1600 & 0.87 & 4.41 & 4.85 & $0-27[1,3,6]$ & $22.9 \%$ & $8.4 \%$ & $3.9 \%$ & $1.80 \%$ \\
\hline (3) PHQ-9 at $12 \mathrm{~m}$ & 1156 & 0.87 & 4.46 & 4.98 & $0-27[1,3,7]$ & $20.4 \%$ & $10.5 \%$ & $3.2 \%$ & $1.80 \%$ \\
\hline (4) GAD-7 at $3 \mathrm{~m}$ & 1514 & 0.90 & 3.29 & 4.20 & $0-21[0,2,5]$ & $18.0 \%$ & $6.4 \%$ & - & $3.10 \%$ \\
\hline (5) GAD-7 at $6 \mathrm{~m}$ & 1601 & 0.90 & 3.14 & 4.10 & $0-21[0,2,5]$ & $18.2 \%$ & $5.2 \%$ & - & $2.70 \%$ \\
\hline (6) GAD-7 at $12 \mathrm{~m}$ & 1160 & 0.90 & 3.11 & 4.03 & $0-21[0,2,5]$ & $17.8 \%$ & $5.5 \%$ & - & $2.50 \%$ \\
\hline
\end{tabular}

Notes: PHQ-9 = Patient Health Questionnaire-9; GAD-7 = General Anxiety Disorder-7; 3/6/12 m = 3/6/12-month post-TBI; Q1 = first quartile, 25\%; Q2 = second quartile or median, 50\%; Q3 = third quartile, $75 \%$; * Cut-offs for different levels of major depression (MD) based on PHQ-9 scores were: 5-9 for mild MD, 10-14 for moderate MD, 15-19 for moderately severe MD, and above 20 for severe MD; and Cut-offs for different levels of generalized anxiety disorder (GAD) based on GAD-7 scores were: 5-9 for mild GAD, 10-14 for moderate GAD, and above 15 for severe GAD.

\subsection{Longitudinal Cross-Lagged Model}

As shown in Table 3, the longitudinal MI of the latent constructs of MD and GAD was supported by formal testing (Online Supplemental Notes 3.1). The ARCL model with the best fit is presented in Figure 2 (see Table 4 and Online Supplemental Notes 3.2 concerning model selection; see Online Supplemental Table S8 concerning latent structure). Cross-sectional correlations between MD and GAD at all time points were high despite a significant decrease over time $\left(\chi^{2}(1)=343.867, p<0.001\right)$. High persistency (AR pathways) was found in both disorders after TBI. The impact remained at high levels between adjacent time points (three to six months vs. six to twelve months) and was statistically stable over time $\left(\chi^{2}(1)=3.344, p=0.068\right.$ for MD; $\chi^{2}(1)=2.405, p=0.12$ for GAD), while those between distant time points were lower. Cross-lagged pathways from MD to GAD were both significant from three to six months and from six to twelve months, indicating that $\mathrm{MD}$ at an earlier time point was associated with GAD at a later time point. The extent of such impacts remained at a similar level over time $\left(\chi^{2}(1)=0.290, p=0.59\right.$ for MD). In contrast, CL pathway from GAD to MD were only significant from 6 to 12 months after TBI.

Table 3. Test of longitudinal measurement invariance of the latent constructs of depression and anxiety.

\begin{tabular}{|c|c|c|c|c|c|c|c|c|c|c|c|c|}
\hline \multirow[b]{2}{*}{ Model } & \multicolumn{6}{|c|}{ Major Depression Assessed with the PHQ-9 } & \multicolumn{6}{|c|}{ Generalized Anxiety Disorder Assessed with the GAD-7 } \\
\hline & $x^{2}$ & $d f$ & $p$-Value & CFI & TLI & $\begin{array}{l}\text { RMSEA } \\
{[90 \% \mathrm{CI}]}\end{array}$ & $x^{2}$ & $d f$ & $p$-Value & CFI & TLI & $\begin{array}{l}\text { RMSEA } \\
{[90 \% \mathrm{CI}]}\end{array}$ \\
\hline $\begin{array}{l}\text { Baseline } \\
\text { model }\end{array}$ & 980.700 & 294 & $<0.001$ & 0.982 & 0.979 & $\begin{array}{c}0.037 \\
{[0.035-0.040]}\end{array}$ & 635.441 & 165 & $<0.001$ & 0.990 & 0.987 & $\begin{array}{c}0.041 \\
{[0.038-0.045]}\end{array}$ \\
\hline $\begin{array}{l}\text { Loading } \\
\text { invariance }\end{array}$ & 998.087 & 310 & $<0.001$ & 0.982 & 0.980 & $\begin{array}{c}0.036 \\
{[0.034-0.039]}\end{array}$ & 665.040 & 177 & $<0.001$ & 0.989 & 0.987 & $\begin{array}{c}0.040 \\
{[0.037-0.044]}\end{array}$ \\
\hline $\begin{array}{l}\text { Threshold } \\
\text { invariance }\end{array}$ & 1004.896 & 344 & $<0.001$ & 0.983 & 0.983 & $\begin{array}{c}0.034 \\
{[0.031-0.036]}\end{array}$ & 675.662 & 203 & $<0.001$ & 0.990 & 0.989 & $\begin{array}{c}0.037 \\
{[0.034-0.040]}\end{array}$ \\
\hline $\begin{array}{l}\text { Unique factor } \\
\text { invariance }\end{array}$ & 910.185 & 362 & $<0.001$ & 0.986 & 0.986 & $\begin{array}{c}0.030 \\
{[0.028-0.032]}\end{array}$ & 621.769 & 217 & $<0.001$ & 0.991 & 0.991 & $\begin{array}{c}0.033 \\
{[0.030-0.036]}\end{array}$ \\
\hline
\end{tabular}

Notes: PHQ-9 = Patient Health Questionnaire-9; GAD-7 = General Anxiety Disorder-7; CFI = comparative fit index; TLI = Tucker-Lewis index; RMSEA = root mean square error of approximation; and $90 \% \mathrm{CI}=$ confidence interval (lower bound and upper bound in square brackets). 


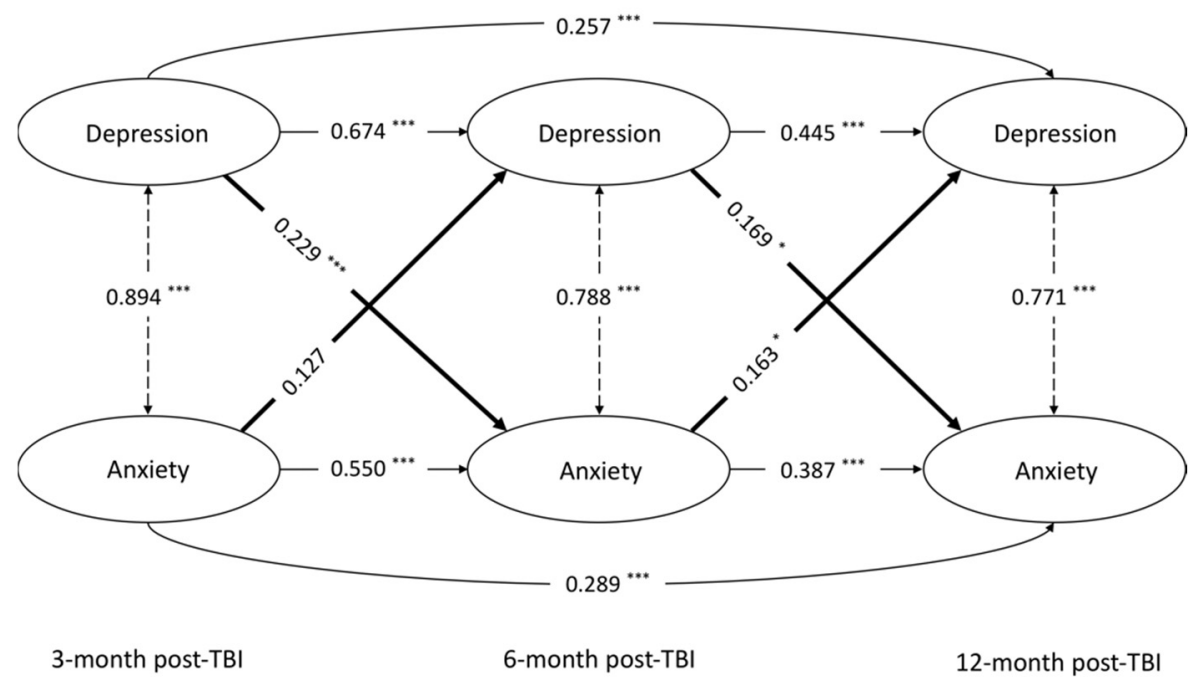

Figure 2. Reciprocal relations between depression and anxiety three to twelve months after TBI stated by model $3(\mathrm{~N}=1683)$. Cross-sectional correlations between depression and anxiety are shown in dotted lines. Autoregressive and cross-lagged effects are shown in solid and bold lines, respectively. All estimates are standardized. This model accounted for $62.4 \%$ and 66.0 of total variance in depression at six and twelve months after TBI, and $58.0 \%$ and $62.0 \%$ of total variance in anxiety at six and twelve months after TBI. ${ }^{* * *} p<0.001$, and ${ }^{*} p<0.05$.

Table 4. Model selection criteria to determine the best fitting model of the reciprocal relations between MD and GAD after TBI.

\begin{tabular}{|c|c|c|c|c|c|c|c|}
\hline & Model & $x^{2}$ & $d f$ & $p$-Value & CFI & TLI & RMSEA [90\%CI] \\
\hline 1 & $\begin{array}{l}\text { autoregressive paths between } \\
\text { adjacent time points }\end{array}$ & 2522.981 & 1025 & $<0.001$ & 0.982 & 0.980 & $0.029[0.028-0.031]$ \\
\hline 2 & $\begin{array}{l}\text { add cross-lagged paths } \\
\text { between adjacent time points }\end{array}$ & 2523.358 & 1021 & $<0.001$ & 0.982 & 0.980 & $0.030[0.028-0.031]$ \\
\hline 3 & $\begin{array}{l}\text { add autoregressive paths } \\
\text { between distant time points }\end{array}$ & 2338.889 & 1019 & $<0.001$ & 0.984 & 0.983 & $0.028[0.026-0.029]$ \\
\hline 4 & $\begin{array}{l}\text { add cross-lagged paths } \\
\text { between distant time points }\end{array}$ & 2347.931 & 1017 & $<0.001$ & 0.984 & 0.983 & $0.028[0.026-0.029]$ \\
\hline
\end{tabular}

Notes: Models 1 through 4 were nested within each other. $\mathrm{CFI}=$ comparative fit index; TLI $=$ Tucker-Lewis index; RMSEA = root mean square error of approximation; and $90 \% \mathrm{CI}=$ confidence interval (lower bound and upper bound in square brackets). The final model is shown in bold font.

\subsection{Factors Associated with Higher Levels of $M D$ and GAD after TBI}

Potential risk factors for MD and GAD levels after TBI were added into the ARCL model separately as baseline covariates (Table 5). Including covariates did not affect the model fit or the existing pathways of the final model. Being female, having stayed at an ICU, having MEI or poorer functional recovery at six months after TBI were strongly associated with more severe MD and GAD after TBI even after Bonferroni corrections. Being without a stable relationship, having more severe injury and major trauma were associated with increased levels of MD only. In contrast, being younger was associated with more GAD. Employment status and years of education showed no predictive value for the level of MD and GAD after TBI. 
Table 5. Risk factors for higher levels of depression and anxiety after TBI.

\begin{tabular}{|c|c|c|c|c|c|}
\hline \multirow[b]{2}{*}{ Covariate $^{1}$} & \multirow[b]{2}{*}{ Reference } & \multicolumn{2}{|c|}{ Depression } & \multicolumn{2}{|c|}{ Anxiety } \\
\hline & & $\beta^{3}$ & $p$-Value ${ }^{4}$ & $\beta^{3}$ & $p$-Value ${ }^{4}$ \\
\hline Sex & Male & 0.211 & $<0.001$ & 0.207 & $<0.001$ \\
\hline Age & - & -0.068 & 0.020 & -0.088 & 0.0030 \\
\hline Years of education & - & -0.057 & 0.086 & -0.046 & 0.158 \\
\hline $\begin{array}{l}\text { Employment } \\
\text { status }\end{array}$ & Employed & -0.047 & 0.44 & -0.102 & 0.098 \\
\hline $\begin{array}{l}\text { Relationship status } \\
\text { Clinical pathway }\end{array}$ & Stable relationship & 0.172 & 0.0042 & 0.106 & 0.080 \\
\hline ER & Adm & 0.051 & 0.047 & 0.006 & 0.85 \\
\hline ICU & Adm & 0.333 & $<0.001$ & 0.222 & $<0.001$ \\
\hline GCS score & - & -0.110 & $<0.001$ & -0.043 & 0.15 \\
\hline MEI & No & 0.244 & $<0.001$ & 0.231 & $<0.001$ \\
\hline Major trauma & No & 0.219 & $<0.001$ & 0.154 & 0.0093 \\
\hline $\begin{array}{c}\text { GOSE score at } 6 \mathrm{~m} \\
\text { after TBI }^{2}\end{array}$ & - & -0.443 & $<0.0001$ & -0.337 & $<0.001$ \\
\hline & - & -0.216 & $<0.001$ & -0.142 & $<0.001$ \\
\hline
\end{tabular}

Notes: $\mathrm{TBI}=$ Traumatic Brain Injury; $\mathrm{ADM}=$ admission to a hospital ward; ER = Emergency Room; ICU = Intensive Care Unit; GCS = Glasgow Coma Scale; MEI = Major Extracranial Injury; and GOSE = Glasgow Outcome Scale, Extended. ${ }^{1}$ Age, years of education, number of psychiatric problems prior to TBI, GCS and GOSE were used as continuous covariates. All other variables were used as nominal covariates with a reference category. All variables were measured at baseline, except the GOSE score at six months after TBI. ${ }^{2}$ The first row shows depression and anxiety at six months after TBI, the second row indicates depression and anxiety at twelve months after TBI. ${ }^{3}$ The $\beta$ coefficient of continuous covariates represents how many units/standard deviations of change in depression or anxiety will occur per unit/standard deviation of change in the continuous covariate. The $\beta$ coefficient of the nominal covariates represents how many units/standard deviations of change in depression or anxiety will be observed when compared with the reference category. ${ }^{4} p$ values in bold are significant after Bonferroni correction with the significance threshold at 0.050/12 $=0.0042$.

\section{Discussion}

To our knowledge, this study presents the first attempt to explore the interplay between MD and GAD within twelve months across all TBI severity groups. Our findings demonstrate a bi-directional association between these two psychiatric disorders throughout this time period.

The levels of both MD and GAD decreased among individuals after TBI during the first year post-injury, which is in line with previous studies [28,29]. However, when the prevalence of moderate to severe MD was inspected, an increase was seen from six to twelve months after TBI, which may reflect a later onset of more chronic MD symptoms in the developmental course of MD during the first year after TBI [56]. The rates of moderate to severe MD and GAD were lower than those reported in recent meta-analyses $[9,10]$, which may be due to the assessment tools and the application of stricter cut-offs. Nonetheless, our considerable moderate to severe rates of MD and GAD warrant paying closer attention to these problems. Whether one views them as outcomes after experiencing TBI or as determinants of the outcome, they may hamper the recovery process. Interventions tackling MD and GAD may mitigate adverse effects on functional recovery as well as the psychological health of those affected.

Despite the substantial proportion of patients suffering from MD and/or GAD symptoms after TBI, only very few of them received psychological support or therapy during rehabilitation, with data on interventions unavailable in over three quarters of the patients. This gap between needs and supply in terms of assessing patients, diagnosis of anxiety and depression and providing therapy, calls for a better monitoring of the psychiatric status and psychological functioning of individuals after TBI.

MD and GAD after TBI had moderate stability and strong concurrent associations, which is in line with previous research on the persistence of psychiatric problems $[29,57]$ and the frequently reported coexistence of depression and anxiety following TBI [2,17-19,22].

Together, these findings emphasize the importance of early diagnosis and interventions. MD and GAD should be assessed at the earliest convenience after TBI and they should always be screened together. In the event of one such problem already being con- 
firmed, patients should be screened for the other problem without undue delay. Patients found to be positive should be further assessed by clinicians using standardized interviews to obtain a differentiated robust diagnosis. Medical treatment of MD and GAD should follow as soon as possible after the diagnosis.

MD and GAD should also be assessed longitudinally. MD at three and six months after TBI significantly impacted patient-reported GAD at a later adjacent time point, i.e., at six and twelve months after TBI. In contrast, GAD-driven impacts were only significant for GAD at six months after TBI influencing MD at twelve months after TBI. These cross-lagged effects are over and above the within-domain persistence of MD and GAD and concurrent associations between MD and GAD. Therefore, these findings may help to determine the target of potential interventions at different stages after TBI. Considering depression at three months after TBI which leads to both, later depression and anxiety, we suggest that treatment after TBI may firstly focus on depression. In contrast, from six months after TBI onwards, equal attention should be paid to depression and anxiety as then they begin to have bidirectional impacts on each other.

Taken together, MD and GAD after TBI display an interplay of comorbid psychiatric and psychological problems. The decreased stability of MD and GAD from six to twelve months post-TBI (relative to three to six) sheds light on the potential of individual resilience, highlighting the importance of targeting this to promote psychological as well as functional recovery during and after rehabilitation [58-60]. Treatment programs, such as Cognitive Behavioral Therapy (CBT), mindfulness-based interventions, or Acceptance and Commitment Therapy (ACT), may be helpful in coping with MD and GAD and prevent persisting affective disorders.

Our results are consistent with the acknowledged vulnerability of females for anxiety and depression $[61,62]$. We were able to identify the protective role of being in a stable relationship for decreasing the risk of developing MD after TBI, which had not been revealed by previous research $[34,63]$. Poorer functional recovery was associated with more severe MD and GAD after TBI, which is consistent with previous findings [37,64]. However, previous evidence from cross-lagged models suggests that functional disabilities have limited temporal influence on mental health problems beyond cross-sectional associations [30,31].

Individuals with concomitant MEI displayed increased levels of MD and GAD after TBI. Our findings add to the scarce knowledge about the impact of mental health problems after TBI in individuals with MEI, who are very often excluded from studies on outcomes after TBI to avoid bias [65]. Until recently, only Carroll et al. [38] had rigorously investigated the association between depression and MEI after TBI and found that in patients with mild TBI, those with additional MEI were more likely to suffer from moderate to severe depression compared with those with isolated TBI. The association between MEI and elevated levels of GAD in our study adds to this knowledge and echoes mouse model findings reporting that anxiety-related behavior appears in mice after TBI with MEI but not in mice after isolated TBI [66]. Taken together, our findings suggest that anxiety after TBI may be caused by concomitant injury in non-head and neck regions rather than TBI itself. This hypothesis may explain our finding on the level of consciousness and major trauma after TBI, that individuals with more severe TBI and major trauma suffered from increased depression but not anxiety. Another finding supporting this is that patients from ICUs, a clinical pathway for which we assume that patients have usually suffered more severe TBI and polytrauma, reported both more severe depression and anxiety. These findings, together with inconsistent previous evidence [33], encourage further investigations to deepen our understanding concerning the neuropathology of mood disorders after TBI. For example, recent studies have identified changes in the white-matter microstructure and functional connectivity, providing support for a neurobiological basis of post-TBI mood/depressive disorders in more severe TBI [67,68].

The differential impact of depression and anxiety may pose important challenges to rehabilitation and recovery after TBI, if these mental problems are not diagnosed and treated early on during the clinical pathway. Additionally, also other psychological problems such 
as posttraumatic stress disorder may hamper recovery, which needs to be investigated in future research. Furthermore, it is of utter importance to also include the assessment of severity of TBI, as it is associated with depression combined with MEIs as they are associated with depression and anxiety and may therefore influence the recovery of individuals after TBI negatively.

This study has several strengths. Conducted using a large sample of the individuals after TBI in Europe and Israel, this study provides more stable results than studies with small samples. In addition, the study not only investigated all TBI severity groups, which allows TBI-severity-dependent conclusions to be drawn, but also includes a MEI assessment, enabling a differentiation of MD and GAD caused by head and non-head injuries.

A number of limitations need to be considered when interpreting the findings. First, although in line with current response rates in TBI research [15], participants in the current study were unevenly distributed with respect to the three clinical pathways. Due to the study design, outcome data were only collected up until six months post-injury among ER patients. Therefore, findings during the period of six to twelve months after TBI may not reflect the true effect among those from ERs and should be interpreted with caution. Second, the PHQ-9 and GAD-7 used for screening MD and GAD symptoms are both PROMs. Moreover, the reliance on a single source of information may introduce a rater bias [69] and the use of PROMs may inflate symptom reporting $[9,10]$. Therefore, future studies might benefit from consolidating self-reported screening instruments with standardized diagnostic interviews led by clinicians, such as the Mini International Neuropsychiatric Interview (MINI) [70] or the Structured Clinical Interview for DSM-5 disorders [71]. Also, somatic symptoms related to functional recovery status, for example, post-injury pain and fatigue, could potentially have an influence. Yet, they were not included in the current study due to the lack of valid corresponding data. Future studies should consider these factors. Furthermore, to avoid protentional bias, we excluded those individuals who reported having psychiatric problems prior to the TBI. Additional investigations focussing on this group and the reciprocity of anxiety and depression after TBI could not be performed due to the number of observations being too small for constructing latent factors and applying the cross-lagged analyses. However, the issue of anxiety and depression in this vulnerable group after TBI needs to be investigated in future studies. Additionally, a high proportion of missing information concerning the psychological services provided after TBI may limit drawing reliable conclusions about rehabilitation after hospital discharge. Finally, data were only available on the patients' MD and GAD for the first year post-TBI. Future studies are warranted which examine this relationship over a longer period of time to deepen the understanding of the extent and complexity of factors that may modulate the development and trajectories of MD and GAD after TBI. In addition, studies are required to provide insight into the mechanisms of the association between depression, anxiety, functional recovery and rehabilitation outcomes after TBI, for which our study was not designed.

\section{Conclusions}

Based on a large European collaborative longitudinal study of patients with a clinical diagnosis of TBI, our findings provide new insights into the understanding of the longitudinal development and interplay of MD and GAD over the first year after TBI. Our results indicate that patient-reported MD and GAD are highly persistent and correlated after TBI. The longitudinal relationship between MD and GAD is reciprocal, with positive bi-directional impacts on each other. Being female, being admitted to an ICU, and being more severely disabled were risk factors associated with suffering from more severe MD and GAD. Injury-related factors were positively linked with MD and GAD after TBI. More specifically, MEI and major trauma was associated with both, whereas severity of TBI was only associated with MD. Our findings strongly suggest that early screening for and treatment of MD and GAD should be conducted in TBI patients to support rehabilitation within the first year post-injury. 
Supplementary Materials: The following materials are available online at https://www.mdpi. com/article/10.3390/jcm10235597/s1, Supplemental Notes 1: Measures of Patient Characteristics (1.1. Sociodemographic factors, 1.2. Injury-related factors), Supplemental Notes 2: Statistical Analysis (2.1. Descriptive statistics and item characteristics, 2.2. Longitudinal measurement invariance, 2.3. Autoregressive cross-lagged models, 2.4. Risk factors), Supplemental Notes 3: Results (3.1. Longitudinal measurement invariance, 3.2. Model selection). Supplemental Table S1: Categorical variables of selected and unselected individuals, Supplemental Table S2: Continuous variables of selected and unselected individuals, Supplemental Table S3: Unselected individuals with psychiatric/psychological problems prior to TBI, Supplemental Table S4: Participants with valid measurements of depression and anxiety after TBI per clinical pathway, Supplemental Table S5: Descriptive statistics of detailed symptoms of depression and anxiety after TBI, Supplemental Table S6: Moderate to severe rate of depression and anxiety according to TBI with and without MEI, Supplemental Table S7: Psychological treatment at 3, 6 and 12 months during rehabilitation after TBI, Supplemental Table S8: Latent structure of depression and anxiety after TBI. Appendix 1: The CENTER-TBI participants and investigators, Appendix 2: STROBE Statement, Supplemental References.

Author Contributions: B.W. and N.v.S. conceived and designed the study. N.v.S. acquired funding for the study. B.W. and M.Z. prepared the data. B.W. analyzed the data. B.W., M.Z., Y.-J.W., T.A. and N.v.S. wrote the first draft of the paper. B.W., M.Z., K.R., Y.-J.W., A.C., I.M., J.A.H., S.P., D.M., T.A., N.A. and N.v.S. interpreted the data and contributed to the writing and editing of the paper. All authors have read and agreed to the published version of the manuscript.

Funding: CENTER-TBI was supported by the European Union 7th Framework program (EC grant 602150). Additional funding was obtained from the Hannelore Kohl Stiftung (Germany), from OneMind (USA), from Integra LifeSciences Corporation (USA) and from Neurotrauma Sciences (USA). The funders of the study had no role in study design, data collection, data analysis, data interpretation, or writing of the report.

Institutional Review Board Statement: The CENTER-TBI study (EC grant 602150) has been conducted in accordance with all relevant laws of the European Union (EU) if directly applicable or of direct effect and all relevant laws of the country where the recruiting sites were located. Informed consent by the patients and/or the legal representative/next of kin was obtained, accordingly to the local legislations, for all patients recruited in the Core Dataset of CENTER-TBI and documented in the electronic case report form (e-CRF). For the full list of sites, ethical committees, and ethical approval details, see the official CENTER-TBI website (https:/ / www.center-tbi.eu/project/ethical-approval, accessed on 4 November 2021).

Informed Consent Statement: Informed consent was obtained from all subjects involved in the study.

Data Availability Statement: All relevant data are available upon request from CENTER-TBI, and the authors are not legally allowed to share it publicly. The authors confirm that they received no special access privileges to the data. CENTER-TBI is committed to data sharing and in particular to responsible further use of the data. Hereto, we have a data sharing statement in place: https: / / www.center-tbi.eu/data/sharing, accessed on 4 November 2021. The CENTER-TBI Management Committee, in collaboration with the General Assembly, established the Data Sharing policy, and Publication and Authorship Guidelines to assure correct and appropriate use of the data as the dataset is hugely complex and requires help of experts from the Data Curation Team or Bio- Statistical Team for correct use. This means that we encourage researchers to contact the CENTER-TBI team for any research plans and the Data Curation Team for any help in appropriate use of the data, including sharing of scripts. Requests for data access can be submitted online: https:/ / www.center-tbi.eu/data, accessed on 4 November 2021. The complete Manual for data access is also available online: https:/ / www.center-tbi.eu/files/SOP-Manual-DAPR-20181101.pdf, accessed on 4 November 2021.

Acknowledgments: We are very grateful to our patients with TBI for participating in this study.

Conflicts of Interest: The authors declare no conflict of interests.

\section{References}

1. Maas, A.I.R.; Menon, D.K.; Adelson, P.D.; Andelic, N.; Bell, M.J.; Belli, A.; Bragge, P.; Brazinova, A.; Büki, A.; Chesnut, R.; et al. Traumatic brain injury: Integrated approaches to improve prevention, clinical care, and research. Lancet Neurol. 2017, 16, 987-1048. [CrossRef] 
2. Bombardier, C.H.; Fann, J.R.; Temkin, N.R.; Esselman, P.C.; Barber, J.; Dikmen, S.S. Rates of major depressive disorder and clinical outcomes following traumatic brain injury. JAMA 2010, 303, 1938-1945. [CrossRef] [PubMed]

3. Mallya, S.; Sutherland, J.; Pongracic, S.; Mainland, B.; Ornstein, T.J. The manifestation of anxiety disorders after traumatic brain injury: A review. J. Neurotrauma 2015, 32, 411-421. [CrossRef]

4. Osborn, A.; Mathias, J.; Fairweather-Schmidt, A.; Anstey, K. Anxiety and comorbid depression following traumatic brain injury in a community-based sample of young, middle-aged and older adults. J. Affect. Disord. 2017, 213, 214-221. [CrossRef] [PubMed]

5. Huda, M.F.; Mohanty, S.; Sharma, V.; Tiwari, Y.; Choudhary, A.; Singh, V.P. Double extradural hematoma: An analysis of 46 cases. Neurol. India 2004, 52, 450-452.

6. Hoffman, A.N.; Taylor, A.N. Stress reactivity after traumatic brain injury: Implications for comorbid post-traumatic stress disorder. Behav. Pharmacol. 2019, 30, 115-121. [CrossRef]

7. Chen, J.-K.; Johnston, K.M.; Petrides, M.; Ptito, A. Neural substrates of symptoms of depression following concussion in male athletes with persisting postconcussion symptoms. Arch. Gen. Psychiatry 2008, 65, 81-89. [CrossRef] [PubMed]

8. Jorge, R.; Robinson, R.G. Mood disorders following traumatic brain injury. Int. Rev. Psychiatry 2003, 15, 317-327. [CrossRef]

9. Osborn, A.; Mathias, J.; Fairweather-Schmidt, A. Depression following adult, non-penetrating traumatic brain injury: A metaanalysis examining methodological variables and sample characteristics. Neurosci. Biobehav. Rev. 2014, 47, 1-15. [CrossRef]

10. Osborn, A.J.; Mathias, J.L.; Fairweather-Schmidt, A.K. Prevalence of anxiety following adult traumatic brain injury: A metaanalysis comparing measures, samples and postinjury intervals. Neuropsychology 2016, 30, 247-261. [CrossRef]

11. Gilbody, S.; Richards, D.; Brealey, S.; Hewitt, C. Screening for depression in medical settings with the Patient Health Questionnaire (PHQ): A diagnostic meta-analysis. J. Gen. Intern. Med. 2007, 22, 1596-1602. [CrossRef]

12. Corrigan, J.D.; Hammond, F.M. Traumatic brain injury as a chronic health condition. Arch. Phys. Med. Rehabil. 2013, 94, 1199-1201. [CrossRef] [PubMed]

13. Jorge, R.E.; Robinson, R.G.; Starkstein, S.E.; Arndt, S. Influence of major depression on 1-year outcome in patients with traumatic brain injury. J. Neurosurg. 1994, 81, 726-733. [CrossRef]

14. Steadman-Pare, D.; Colantonio, A.; Ratcliff, G.; Chase, S.; Vernich, L. Factors associated with perceived quality of life many years after traumatic brain injury. J. Head Trauma Rehabil. 2001, 16, 330-342. [CrossRef] [PubMed]

15. Rauen, K.; Reichelt, L.; Probst, P.; Schäpers, B.; Müller, F.; Jahn, K.; Plesnila, N. Quality of life up to 10 years after traumatic brain injury: A cross-sectional analysis. Health Qual. Life Outcomes 2020, 18, 166. [CrossRef]

16. Rockhill, C.M.; Jaffe, K.; Zhou, C.; Fan, M.-Y.; Katon, W.; Fann, J.R. Health care costs associated with traumatic brain injury and psychiatric illness in adults. J. Neurotrauma 2012, 29, 1038-1046. [CrossRef]

17. Hanel, G.; Henningsen, P.; Herzog, W.; Sauer, N.; Schaefert, R.; Szecsenyi, J.; Löwe, B. Depression, anxiety, and somatoform disorders: Vague or distinct categories in primary care? Results from a large cross-sectional study. J. Psychosom. Res. 2009, 67, 189-197. [CrossRef]

18. Van der Horn, H.J.; Spikman, J.M.; Jacobs, B.; van der Naalt, J. Postconcussive complaints, anxiety, and depression related to vocational outcome in minor to severe traumatic brain injury. Arch. Phys. Med. Rehabil. 2013, 94, 867-874. [CrossRef]

19. Hirschfeld, R.M. The comorbidity of major depression and anxiety disorders: Recognition and management in primary care. Prim. Care Companion J. Clin. Psychiatry 2001, 3, 244. [CrossRef] [PubMed]

20. Jorge, R.E.; Robinson, R.G.; Moser, D.; Tateno, A.; Crespo-Facorro, B.; Arndt, S. Major depression following traumatic brain injury. Arch. Gen. Psychiatry 2004, 61, 42-50. [CrossRef] [PubMed]

21. Kroenke, K.; Spitzer, R.L.; Williams, J.B.; Löwe, B. The patient health questionnaire somatic, anxiety, and depressive symptom scales: A systematic review. Gen. Hosp. Psychiatry 2010, 32, 345-359. [CrossRef]

22. Whelan-Goodinson, R.; Ponsford, J.L.; Schönberger, M.; Johnston, L. Predictors of psychiatric disorders following traumatic brain injury. J. Head Trauma Rehabil. 2010, 25, 320-329. [CrossRef]

23. Teymoori, A.; Gorbunova, A.; Haghish, F.E.; Real, R.; Zeldovich, M.; Wu, Y.J.; Polinder, S.; Asendorf, T.; Menon, D.; Steinbuchel, N. Factorial structure and validity of depression (PHQ-9) and anxiety (GAD-7) scales after traumatic brain injury. J. Clin. Med. 2020, 9, 873. [CrossRef] [PubMed]

24. Osman, A.; Wong, J.L.; Bagge, C.L.; Freedenthal, S.; Gutierrez, P.M.; Lozano, G. The Depression Anxiety Stress Scales-21 (DASS-21): Further examination of dimensions, scale reliability, and correlates. J. Clin. Psychol. 2012, 68, 1322-1338. [CrossRef] [PubMed]

25. Zigmond, A.S.; Snaith, R.P. The hospital anxiety and depression scale. Acta Psychiatr. Scand. 1983, 67, 361-370. [CrossRef] [PubMed]

26. WHO. International Statistical Classification of Diseases and Related Health Problems, 11th ed.; WHO: Geneva, Switzerland, 2020.

27. American Psychiatric Association. Diagnostic and Statistical Manual of Mental Disorders (DSM-5®); American Psychiatric Pub: Washington, DC, USA, 2013.

28. Barker-Collo, S.; Theadom, A.; Jones, K.; Starkey, N.; Kahan, M.; Feigin, V.L. Depression and anxiety across the first 4 years after mild traumatic brain injury: Findings from a community-based study. Brain Inj. 2018, 32, 1651-1658. [CrossRef]

29. Ren, D.; Fan, J.; Puccio, A.M.; Okonkwo, D.O.; Beers, S.R.; Conley, Y. Group-based trajectory analysis of emotional symptoms among survivors after severe traumatic brain injury. J. Head Trauma Rehabil. 2017, 32, E29-E37. [CrossRef] [PubMed]

30. Zahniser, E.; Nelson, L.D.; Dikmen, S.S.; Machamer, J.E.; Stein, M.B.; Yuh, E.L.; Manley, G.T.; Temkin, N.R.; Adeoye, O.; Badjatia, N.; et al. The temporal relationship of mental health problems and functional limitations following mTBI: A TRACK-TBI and TED study. J. Neurotrauma 2019, 36, 1786-1793. [CrossRef] [PubMed] 
31. Perrin, P.; Stevens, L.F.; Sutter, M.; Lequerica, A.H.; Krch, D.; Kolakowsky-Hayner, S.A.; Arango-Lasprilla, J.C. Reciprocal causation between functional independence and mental health 1 and 2 years after traumatic brain injury: A cross-lagged panel structural equation model. Am. J. Phys. Med. Rehabil. Jun 2017, 96, 374-380. [CrossRef] [PubMed]

32. Gould, K.R.; Ponsford, J.L.; Johnston, L.; Schönberger, M. The nature, frequency and course of psychiatric disorders in the first year after traumatic brain injury: A prospective study. Psychol. Med. 2011, 41, 2099-2109. [CrossRef] [PubMed]

33. Scholten, A.C.; Haagsma, J.A.; Cnossen, M.C.; Olff, M.; Van Beeck, E.F.; Polinder, S. Prevalence of and risk factors for anxiety and depressive disorders after traumatic brain injury: A systematic review. J. Neurotrauma 2016, 33, 1969-1994. [CrossRef] [PubMed]

34. Demakis, G.J.; Hammond, F.M.; Knotts, A. Prediction of depression and anxiety 1 year after moderate-severe traumatic brain injury. Appl. Neuropsychol. 2010, 17, 183-189. [CrossRef]

35. Rao, V.; Bertrand, M.; Rosenberg, P.; Makley, M.; Schretlen, D.J.; Brandt, J.; Mielke, M. Predictors of new-onset depression after mild traumatic brain injury. J. Neuropsychiatry Clin. Neurosci. 2010, 22, 100-104. [CrossRef] [PubMed]

36. Levin, H.S.; McCauley, S.R.; Josic, C.P.; Boake, C.; Brown, S.A.; Goodman, H.S.; Merritt, S.G.; Brundage, S.I. Predicting depression following mild traumatic brain injury. Arch. Gen. Psychiatry 2005, 62, 523-528.

37. Deb, S.; Burns, J. Neuropsychiatric consequences of traumatic brain injury: A comparison between two age groups. Brain Inj. 2007, 21, 301-307. [CrossRef]

38. Carroll, E.L.; Manktelow, A.E.; Outtrim, J.G.; Chatfield, D.; Forsyth, F.; Hutchinson, P.J.A.; Tenovuo, O.; Posti, J.P.; Wilson, L.; Sahakian, B.J.; et al. Influence of concomitant extracranial injury on functional and cognitive recovery from mild versus moderate to severe traumatic brain injury. J. Head Trauma Rehabil. 2020, 35, E513-E523. [CrossRef]

39. Maas, A.I.; Menon, D.K.; Steyerberg, E.W.; Citerio, G.; Lecky, F.; Manley, G.T.; Hill, S.; Legrand, V.; Sorgner, A.; CENTER-TBI Participants and Investigators. Collaborative european neurotrauma effectiveness research in traumatic brain injury (center-tbi) a prospective longitudinal observational study. Neurosurgery 2015, 76, 67-80. [CrossRef]

40. Steyerberg, E.W.; Wiegers, E.; Sewalt, C.; Buki, A.; Citerio, G.; De Keyser, V.; Ercole, A.; Kunzmann, K.; Lanyon, L.; Lecky, F.; et al. Case-mix, care pathways, and outcomes in patients with traumatic brain injury in CENTER-TBI: A European prospective, multicentre, longitudinal, cohort study. Lancet Neurol. 2019, 18, 923-934. [CrossRef]

41. Teasdale, G.; Maas, A.; Lecky, F.; Manley, G.; Stocchetti, N.; Murray, G. The glasgow coma scale at 40 years: Standing the test of time. Lancet Neurol. 2014, 13, 844-854. [CrossRef]

42. Gennarelli, T.A.; Wodzin, E. AIS 2005: A contemporary injury scale. Injury 2006, 37, 1083-1091. [CrossRef]

43. Sewalt, C.A.; Venema, E.; Wiegers, E.J.A.; Lecky, F.E.; Schuit, S.C.E.; Hartog, D.D.; Steyerberg, E.W.; Lingsma, H.F. Trauma models to identify major trauma and mortality in the prehospital setting. Br. J. Surg. 2020, 107, 373. [CrossRef]

44. Van Leeuwen, N.; Lingsma, H.F.; Perel, P.; Lecky, F.; Roozenbeek, B.; Lu, J.; Shakur, H.; Weir, J.; Steyerberg, E.W.; Maas, A.I. Prognostic value of major extracranial injury in traumatic brain injury: An individual patient data meta-analysis in 39,274 patients. Neurosurgery 2012, 70, 811-818. [CrossRef]

45. Wilson, J.L.; Pettigrew, L.E.; Teasdale, G.M. Structured interviews for the glasgow outcome scale and the extended glasgow outcome scale: Guidelines for their use. J. Neurotrauma 1998, 15, 573-585. [CrossRef] [PubMed]

46. Kroenke, K.; Spitzer, R.L.; Williams, J.B. The PHQ-9: Validity of a brief depression severity measure. J. Gen. Intern. Med. 2001, 16, 606-613. [CrossRef] [PubMed]

47. Spitzer, R.L.; Kroenke, K.; Williams, J.B.; Löwe, B. A brief measure for assessing generalized anxiety disorder: The GAD-7. Arch Intern. Med. 2006, 166, 1092-1097. [CrossRef] [PubMed]

48. Bollen, K.A. Structural equation models. Encycl. Biostat. 2005, 7.

49. Curran, P.J.; Bollen, K.A. The Best of Both Worlds: Combining Autoregressive and Latent Curve Models; American Psychological Association: Washington, DC, USA, 2001; pp. 107-135.

50. Masten, A.S.; Cicchetti, D. Developmental cascades. Dev. Psychopathol. 2010, 22, 491-495. [CrossRef] [PubMed]

51. Selig, J.P.; Little, T.D. Autoregressive and Cross-Lagged Panel Analysis for Longitudinal Data; American Psychological Association: Washington, DC, USA, 2012.

52. Kearney, M.W. Cross lagged panel analysis. In The SAGE Encyclopedia of Communication Research Methods; Sage Publications: Thousand Oaks, CA, USA, 2017; pp. 312-314.

53. Muthén, L.; Muthén, B. Mplus Version 7 User's Guide. 1998-2015. In Statistical Analysis with Latent Variables; Muthén \& Muthén: Los Angeles, CA, USA, 2012.

54. Beauducel, A.; Herzberg, P.Y. On the performance of maximum likelihood versus means and variance adjusted weighted least squares estimation in CFA. Struct. Equ. Modeling 2006, 13, 186-203. [CrossRef]

55. R Foundation for Statistical Computing. A Language and Environment for Statistical Computing; R Foundation for Statistical Computing: Vienna, Austria, 2019.

56. Bombardier, C.H.; Hoekstra, T.; Dikmen, S.; Fann, J.R. Depression trajectories during the first year after traumatic brain injury. J. Neurotrauma 2016, 33, 2115-2124. [CrossRef] [PubMed]

57. Alway, Y.; Gould, K.R.; Johnston, L.; McKenzie, D.; Ponsford, J. A prospective examination of Axis I psychiatric disorders in the first 5 years following moderate to severe traumatic brain injury. Psychol. Med. 2016, 46, 1331-1341. [CrossRef] [PubMed]

58. Godwin, E.E.; Lukow, H.R.; Lichiello, S. Promoting resilience following traumatic brain injury: Application of an interdisciplinary, evidence-based model for intervention. Fam. Relat. 2015, 64, 347-362. [CrossRef] 
59. Kreutzer, J.S.; Marwitz, J.H.; Sima, A.; Bergquist, T.F.; Johnson-Greene, D.; Felix, E.R.; Whiteneck, G.G.; Dreer, L.E. Resilience following traumatic brain injury: A traumatic brain injury model systems study. Arch. Phys. Med. Rehabil. 2015, 97, 708-713. [CrossRef]

60. Wardlaw, C.; Hicks, A.J.; Sherer, M.; Ponsford, J.L. Psychological resilience is associated with participation outcomes following mild to severe traumatic brain injury. original research. Front. Neurol. 2018, 9, 563. [CrossRef] [PubMed]

61. Ashman, T.; A Spielman, L.; Hibbard, M.R.; Silver, J.M.; Chandna, T.; A Gordon, W. Psychiatric challenges in the first 6 years after traumatic brain injury: Cross-sequential analyses of Axis I disorders. Arch. Phys. Med. Rehabil. 2004, 85, 36-42. [CrossRef] [PubMed]

62. Whelan-Goodinson, R.; Ponsford, J.; Schönberger, M. Association between psychiatric state and outcome following traumatic brain injury. J. Rehabil. Med. 2008, 40, 850-857. [CrossRef] [PubMed]

63. Seel, R.T.; Kreutzer, J.S.; Rosenthal, M.; Hammond, F.M.; Corrigan, J.D.; Black, K. Depression after traumatic brain injury: A National Institute on Disability and Rehabilitation Research Model Systems multicenter investigation. Arch. Phys. Med. Rehabil. 2003, 84, 177-184. [CrossRef]

64. Alway, Y.; Gould, K.R.; McKay, A.; Johnston, L.; Ponsford, J. Factors associated with posttraumatic stress disorder following moderate to severe traumatic brain injury: A prospective study. Depress. Anxiety 2016, 33, 19-26. [CrossRef]

65. McCauley, S.R.; Boake, C.; Levin, H.S.; Contant, C.F.; Song, J.X. Postconcussional disorder following mild to moderate traumatic brain injury: Anxiety, depression, and social support as risk factors and comorbidities. J. Clin. Exp. Neuropsychol. 2001, 23, 792-808. [CrossRef]

66. Shultz, S.R.; Sun, M.; Wright, D.K.; Brady, R.D.; Liu, S.; Beynon, S.; Schmidt, S.F.; Kaye, A.H.; Hamilton, J.A.; O’brien, T.J. Tibial fracture exacerbates traumatic brain injury outcomes and neuroinflammation in a novel mouse model of multitrauma. J. Cereb. Blood Flow Metab. 2015, 35, 1339-1347. [CrossRef]

67. Spitz, G.; Alway, Y.; Gould, K.R.; Ponsford, J.L. Disrupted white matter microstructure and mood disorders after traumatic brain injury. J. Neurotrauma 2017, 34, 807-815. [CrossRef]

68. Moreno-López, L.; Sahakian, B.; Manktelow, A.; Menon, D.K.; Stamatakis, E.A. Depression following traumatic brain injury: A functional connectivity perspective. Brain Inj. 2016, 30, 1319-1328. [CrossRef] [PubMed]

69. Althubaiti, A. Information bias in health research: Definition, pitfalls, and adjustment methods. J. Multidiscip. Healthc. 2016, 9 , 211-217. [CrossRef] [PubMed]

70. Sheehan, D.V.; Lecrubier, Y.; Sheehan, K.H.; Amorim, P.; Janavs, J.; Weiller, E.; Hergueta, T.; Baker, R.; Dunbar, G.C. The Mini-International Neuropsychiatric Interview (M.I.N.I.): The development and validation of a structured diagnostic psychiatric interview for DSM-IV and ICD-10. J. Clin. Psychiatry 1998, 59, 22-33. [PubMed]

71. First, M.B. Structured clinical interview for the DSM (SCID). In The Encyclopedia of Clinical Psychology; John Wiley \& Sons: Hoboken, NJ, USA, 2014; pp. 1-6. 